\title{
Impacts of ambient air pollution on glucose metabolism in Korean adults: a Korea National Health and Nutrition Examination Survey study
}

Myung-Jae Hwang ${ }^{1}$, Jong-Hun Kim ${ }^{1}$, Youn-Seo Koo ${ }^{2}$, Hui-Young Yun ${ }^{2}$ and Hae-Kwan Cheong ${ }^{1 *}$ (1)

\begin{abstract}
Background: Exposure to air pollution was reported to affect glucose metabolism, increasing the risk of diabetes mellitus. We conducted an epidemiological study on glucose metabolism and air pollution by exploring the levels of fasting blood glucose (FBG) and hemoglobin $\mathrm{A} 1 \mathrm{c}(\mathrm{HbA1c})$ with changes in ambient air quality, depending on the characteristics of the susceptible population.

Methods: We carried out a cross-sectional analysis of a nationally representative sample of 10,014 adults (4267 in male and 5747 in female) from the Korea National Health and Nutrition Examination Survey in 2012 and 2013 along with data from the Korean Air Quality Forecasting System. The analysis was performed using a generalized linear model stratified by sex, age, and presence of diabetes. We assessed the changes in FBG and HbA1c associated with exposures to particulate matter $\left(\mathrm{PM}_{10}\right)$, fine particulate matter $\left(\mathrm{PM}_{2.5}\right)$, and nitrogen dioxide $\left(\mathrm{NO}_{2}\right)$ after controlling for confounders.

Results: There were 1110 participants with diabetes (557 in male and 553 in female). Overall, the FBG level increased by $7.83 \mathrm{mg} / \mathrm{dL}$ (95\% confidence interval [CI]: 2.80-12.87) per interquartile range (IQR) increment of $\mathrm{NO}_{2}$, $5.32 \mathrm{mg} / \mathrm{dL}$ (95\% Cl: 1.22-9.41) per IQR increment of $\mathrm{PM}_{10}$ at a moving average of $0-6$ days, and $4.69 \mathrm{mg} / \mathrm{dL}$ (95\% $\mathrm{Cl}$ : 0.48-8.91) per IQR increment of $\mathrm{PM}_{25}$ at a moving average of $0-5$ days. HbA1c increased by $0.57 \%$ (95\% Cl: $0.04-$ 1.09) per IQR increment of $\mathrm{PM}_{10}$ at a moving average of $0-60$ days and $0.34 \%$ ( $95 \% \mathrm{Cl}$ : 0.04-0.63) per IQR increment of $\mathrm{PM}_{2.5}$ at a moving average of $0-75$ days. The change in FBG and $\mathrm{HbA1c}$ increased more in the diabetic group, especially in males aged 65 years or more. There was a strong association between elevation in diabetes-related parameters and exposure to air pollution.

Conclusions: Our study provides scientific evidence supporting that short- and mid-term exposure to air pollution is associated with changes in biological markers related to diabetes. This finding suggests that the impact of air pollution should be reflected in chronic disease management when establishing local health care policies.
\end{abstract}

Keywords: Air pollution, Korea National Health and nutritional examination survey, Fasting blood sugar, Hemoglobin A1c, Diabetes

\footnotetext{
* Correspondence: hkcheong@skku.edu

1 Department of Social and Preventive Medicine, Sungkyunkwan University

School of Medicine, 2066 Seobu-ro Jangan-gu, Suwon, Gyeonggi-do 16419 Republic of Korea

Full list of author information is available at the end of the article
}

(c) The Author(s). 2020 Open Access This article is licensed under a Creative Commons Attribution 4.0 International License, which permits use, sharing, adaptation, distribution and reproduction in any medium or format, as long as you give appropriate credit to the original author(s) and the source, provide a link to the Creative Commons licence, and indicate if changes were made. The images or other third party material in this article are included in the article's Creative Commons licence, unless indicated otherwise in a credit line to the material. If material is not included in the article's Creative Commons licence and your intended use is not permitted by statutory regulation or exceeds the permitted use, you will need to obtain permission directly from the copyright holder. To view a copy of this licence, visit http://creativecommons.org/licenses/by/4.0/. The Creative Commons Public Domain Dedication waiver (http://creativecommons.org/publicdomain/zero/1.0/) applies to the data made available in this article, unless otherwise stated in a credit line to the data. 


\section{Background}

Exposure to ambient air pollution is a major environmental risk factor in terms of the global burden of disease [1]. Short- and long-term exposure to particulate matter (PM) increases the incidence of respiratory and cardiovascular disease [2], as well as the risk of chronic diseases such as diabetes mellitus (DM) [3, 4]. DM is a disease in which insulin secretion is perturbed, resulting in impaired blood glucose control. Exposure to ambient air pollutants has also been associated with deterioration in blood coagulation and glucose metabolism and effects on gene expression [5-8]. These metabolic disorders are associated with an increase in the levels of fasting blood glucose (FBG) and hemoglobin A1c (HbA1c), which are essential blood markers of DM.

Prolonged inhalation of toxic substances in the atmosphere leads to an increased risk of DM [9-15]. Exposure to nitrogen dioxide $\left(\mathrm{NO}_{2}\right)$ contributes to impaired glucose metabolism [16], while exposure to fine particulate matter $\left(\mathrm{PM}_{2.5}\right)$ resulted in elevated levels of FBG and HbA1c [17, 18]. Chen et al. observed a strong association between daily exposure to air pollutants and changes in FBG levels [19]. Chuang et al. also reported that short-term exposure to $\mathrm{PM}_{10}$ elevated the levels of FBG and HbA1c [20].

However, air pollution does not affect all populations equally because of the differences in sensitivity among susceptible subpopulation [21]. Several previous studies have assessed the effects of short-term exposure to ambient air pollution on the morbidity associated with DM, obesity, and hypertension in susceptible populations [22-24]. In 2012, Kim and Hong showed that increments in $\mathrm{PM}_{10}$ and $\mathrm{NO}_{2}$ levels were significantly associated with changes in blood glucose levels among the elderly population in Seoul, Korea [5]. This study was performed on a panel study upon elderly subjects in a district. Few studies have evaluated some diabetesrelated blood markers that can be used to determine the presence of diabetes based on a general population.

We explored the association between short- and midterm exposure to ambient air pollution and blood markers of DM with a specific focus on susceptibility factors, such as sex, age, and the presence of DM, using the Korea National Health and Nutrition Examination Survey (KNHANES).

\section{Methods}

\section{Study population}

We used the data from the KNHANES, which is an annual nationwide survey conducted by the Korea Centers for Disease Control and Prevention since 1998 [25]. It is a cross-sectional survey composed of a health interview, physical examination, and nutrition survey applied to a nationally representative population [26]. This survey provides representative and reliable statistical data on 23 households from 192 national sampling units on the level of health, health behavior, and food and nutritional intake in the Republic of Korea (South Korea). The sampling framework of the survey uses the latest population and housing survey data available at the time of sample design so that a probability sample can be extracted for those over one year of age living in South Korea. Twostage stratified sampling was applied to select the primary and secondary sampling units. The KNHANES also developed a method for quality control and diagnostic medical examinations to ensure the accuracy of blood test results and conducts internal and external quality control evaluations each year. A total of 7279 in males and 8797 in females participated in the KNHANES in 2012 and 2013. Among them, we recruited those aged 20 years or older.

The present study used the FBG and HbA1c values obtained after the participants had fasted for $8 \mathrm{~h}$ to determine the presence of DM from blood tests. We selected only those who had also responded to the questionnaire among those with data on FBG and HbA1c levels. Participants with FBG levels above 126 $\mathrm{mg} / \mathrm{dL}$ or taking diabetes medications, who received insulin injections, or who had been diagnosed with DM by a physician were classified as being diabetic. We calculated the body mass index (BMI) using the height and weight measured during the health examination. BMI was defined as body weight $(\mathrm{kg})$ divided by the square of height (meters). During the study period, a total of 10 , 014 participants were included in the analysis (4267 in male and 5747 in female).

\section{Definition of covariates}

Individual socioeconomic status (SES) was determined based on the participants' level of education, which was categorized based on the participants' responses to the items in the questionnaire used in the KNHANES: "below elementary school", "middle school", "high school", and "university and over". Alcohol consumption status was categorized as "no", "less than once a week", and "more than once a week" [27]. Physical activity was classified as "no" if no physical activity was performed and "yes" if at least moderate physical activity was performed once a week. Smoking status was categorized as "never smoked", "smoked in the past but not currently", and "currently smoking" [28, 29]. According to BMI, we categorized the participants as "underweight" (BMI < $18.5 \mathrm{~kg} / \mathrm{m}^{2}$ ), "normal" (BMI $\geq 18.5$ and $<25.0 \mathrm{~kg} / \mathrm{m}^{2}$ ), and "obese" $\left(B M I \geq 25.0 \mathrm{~kg} / \mathrm{m}^{2}\right)[30,31]$. The level of FBG (mg/dL) and HbA1c (percentage) per interquartile range (IQR) was adjusted for daily mean temperature, humidity, sex, age, education, alcohol 
consumption, physical activity, smoking, and obesity in Model 3 (Additional file 1: Table S1 and S2).

\section{Exposure modeling}

Of 192 sampling units in the KNHANES, only half had air pollution data measured at air quality monitoring stations. In order to generate air pollution data for all 192 sampling units, a prediction model with data assimilation using data from the Korean Air Quality Forecasting System (KAQFS) was used.

The modeling configuration of the KAQFS consists of the Weather Research and Forecasting model for meteorological modeling, the Sparse Matrix Operator Kernel Emissions system for emission data processing, and the Community Multiscale Air Quality (CMAQ) model for chemical transport simulation over the East Asia region, focusing on the Korean peninsula. The KAQFS, which has been running and open to the public since 2007 (http://www.kaq.or.kr/), was used to forecast the air quality in terms of $\mathrm{PM}_{10}, \mathrm{PM}_{2.5}, \mathrm{SO}_{2}, \mathrm{O}_{3}, \mathrm{CO}$, and $\mathrm{NO}_{2}$ concentrations across South Korea. The anthropogenic emission data from China and Japan were based on the Multi-resolution Emission Inventory for China (http://www.meicmodel.org) for 2010 and the Regional Emission inventory in Asia for 2008 from the National Institute for Environmental Studies, Japan. For the South Korean region, the Clean Air Policy Support System emission inventory by the National Institute for Environmental Research for 2011 was used. The detailed model configurations and corresponding input data have been described elsewhere [32-36].

The data assimilation using surface measurements in China and South Korea was applied to the KAQFS to enhance model performance. The model predictions using the KAQFS with data assimilation showed better agreement with observations than those without it. Choi et al. showed that the spatial distributions of $\mathrm{PM}_{10}$, $\mathrm{PM}_{2.5}$, and $\mathrm{NO}_{2}$ with data assimilation over China and the Korean peninsula accurately depicted the observed air quality at the monitoring stations [36]. Further details of data assimilation are available in Choi et al.'s study, and these data have also been validated in a previous study [36, 37].

The air quality over the Korean peninsula was assessed according to grid sizes of $9 \mathrm{~km} \times 9 \mathrm{~km}$, with a fine grid size of $3 \mathrm{~km} \times 3 \mathrm{~km}$ in the metropolitan areas of Seoul. We used these values to calculate the weighted mean values according to the boundaries of 253 health administrative districts. We estimated the daily concentrations of $\mathrm{PM}_{10}$ (unit: $\mu \mathrm{g} / \mathrm{m}^{3}$ ), $\mathrm{PM}_{2.5}$ (unit: $\mu \mathrm{g} / \mathrm{m}^{3}$ ), and $\mathrm{NO}_{2}$ (unit: parts per billion [ppb]) using the KAQFS data in each region where the KNHANES is conducted. The data were combined by matching the residential address of the participants and the date of the blood test.

\section{Study design}

To assess the susceptibility factors, we stratified the participants into males and females and divided according to age group ( $<65$ and $\geq 65$ years). The changes in FBG and HbA1c levels were then analyzed according to the level of exposure to air pollution. In particular, we observed how the effects of air pollution differed in diabetic and nondiabetic participants. In order to observe changes in FBG levels due to short-term exposure to air pollution, a lag effect from a moving average of $0-10$ days before the date of the blood test ( 0 day [same date of the blood test], $0-1$ days, $0-2$ days, ... 0-10 days) was applied, and the effect of relatively mid-term exposure on HbA1c levels was examined. HbA1c has been widely accepted as the most reliable method for evaluating mid-term blood glucose control in participants with diabetes and reflects the glucose levels in the previous 6-8 weeks as the lifespan of a typical red blood cell is approximately 115 days [38]. HbA1c should not be used for monitoring rapid changes in blood glucose levels $[39,40]$. To estimate the HbA1c level changes due to mid-term exposure to air pollution, we calculated the average exposure by applying the moving averages on days $0,0-10,0-15,0-30,0-45,0-60,0-75,0-90,0-120$, and $0-150$ before the blood test. The changes in FBG and HbA1c levels were analyzed by applying the IQR of air pollutants during the study period.

\section{Statistical analysis}

We used the generalized additive model (GAM) to observe the changes in FBG and HbA1c levels with increasing concentrations of air pollutants. The use of GAM enables a non-linear fit for each variable while maintaining the legibility of existing linear models. We used the generalized linear model, an extension of the linear model, in which the dependent variable is continuous. In each model, the air pollutant value was regarded as an independent variable, while the dependent variables were the levels of FBG and HbA1c in consideration of the lag effect. All models were adjusted for sex, age, level of education, alcohol consumption, physical activity, smoking, obesity, and splined function of daily mean temperature and humidity at the time of exposure. All statistical analyses were performed using SAS version 9.4 (SAS Institute Inc., Cary, NC, USA) and R version 3.5.3 (https://cran.r-project.org/bin/ windows/base/old/3.5.3/). The level of statistical significance was set at $p=0.05$, and the $95 \%$ confidence intervals $(\mathrm{CIs})$ were estimated for the point estimates.

\section{Results}

A total of 4267 in males and 5747 in females were included in the analyses. According to the criteria for diagnosing diabetes, $13.1 \%$ of males and $9.6 \%$ of females had diabetes (Table 1). 
Table 1 Demographic characteristics of the study participants by sex in the Korea National Health and Nutrition Examination Survey (2012-2013)

\begin{tabular}{|c|c|c|c|c|c|c|c|}
\hline \multirow[t]{3}{*}{ Variables } & \multirow{2}{*}{\multicolumn{2}{|c|}{$\frac{\text { Male }}{(n=4267)}$}} & \multirow{2}{*}{\multicolumn{2}{|c|}{$\frac{\text { Female }}{(n=5747)}$}} & \multirow{2}{*}{\multicolumn{2}{|c|}{$\frac{\text { Total }}{(n=10,014)}$}} & \multirow[t]{3}{*}{$\boldsymbol{p}$-value } \\
\hline & & & & & & & \\
\hline & $\bar{N}$ & $\%$ & $\bar{N}$ & $\%$ & $\bar{N}$ & $\%$ & \\
\hline Diabetes $^{a}$ & & & & & & & $<0.0001$ \\
\hline No & 3710 & 86.9 & 5194 & 90.4 & 8904 & 88.9 & \\
\hline Yes & 557 & 13.1 & 553 & 9.6 & 1110 & 11.1 & \\
\hline Age group & & & & & & & 0.565 \\
\hline$<65$ years & 3294 & 77.2 & 4495 & 78.2 & 7789 & 77.8 & \\
\hline$\geq 65$ years & 973 & 22.8 & 1252 & 21.8 & 2225 & 22.2 & \\
\hline Education level & & & & & & & $<0.0001$ \\
\hline Elementary school & 694 & 16.3 & 1651 & 28.8 & 2345 & 23.4 & \\
\hline Middle school & 459 & 10.8 & 589 & 10.2 & 1048 & 10.5 & \\
\hline High school & 1577 & 36.9 & 1858 & 32.3 & 3435 & 34.3 & \\
\hline University and over & 1537 & 36.0 & 1649 & 28.7 & 3186 & 31.8 & \\
\hline Alcohol consumption & & & & & & & $<0.0001$ \\
\hline No & 724 & 17.0 & 2151 & 37.4 & 2875 & 28.7 & \\
\hline Less than once a week & 1994 & 46.7 & 3086 & 53.7 & 5080 & 50.7 & \\
\hline More than once a week & 1549 & 36.3 & 510 & 8.9 & 2059 & 20.6 & \\
\hline Physical activity & & & & & & & $<0.0001$ \\
\hline No & 2338 & 54.7 & 2201 & 38.3 & 4539 & 45.3 & \\
\hline Yes & 1929 & 45.2 & 3546 & 61.7 & 5475 & 54.7 & \\
\hline Smoking & & & & & & & $<0.0001$ \\
\hline Never smoked & 873 & 20.5 & 5160 & 89.8 & 6033 & 60.2 & \\
\hline Past & 1703 & 39.9 & 265 & 4.6 & 1968 & 19.7 & \\
\hline Current & 1691 & 39.6 & 322 & 5.6 & 2013 & 20.1 & \\
\hline Obesity & & & & & & & $<0.0001$ \\
\hline Underweight (BMI: $<18.5 \mathrm{~kg} / \mathrm{m}^{2}$ ) & 96 & 2.2 & 301 & 5.2 & 397 & 63.5 & \\
\hline Normal (BMI: $\geq 18.5$ and $<25.0 \mathrm{~kg} / \mathrm{m}^{2}$ ) & 2601 & 61.0 & 3753 & 65.3 & 6354 & 4.0 & \\
\hline Obesity (BMI: $\geq 25.0 \mathrm{~kg} / \mathrm{m}^{2}$ ) & 1570 & 36.8 & 1693 & 29.5 & 3263 & 32.5 & \\
\hline
\end{tabular}

${ }^{a} p$-values were obtained by comparing the groups using the chi-square test or Fisher's exact test. ${ }^{\ddagger}$ Participants with FBG levels above 126 mg/dL or taking diabetes medications, who received insulin injections, or who had been diagnosed with DM by a physician were classified as being diabetic

The mean levels of exposure to $\mathrm{PM}_{10}$ and $\mathrm{PM}_{2.5}$ were 42.1 and $32.1 \mu \mathrm{g} / \mathrm{m}^{3}$, respectively, twice as high as the World Health Organization's annual recommendation (20 and $10 \mu \mathrm{g} / \mathrm{m}^{3}$, respectively). The mean level of exposure to $\mathrm{NO}_{2}$ was $23.5 \mathrm{ppb}$. The IQRs of $\mathrm{PM}_{10}, \mathrm{PM}_{2.5}$, and $\mathrm{NO}_{2}$ were $23.5 \mu \mathrm{g} / \mathrm{m}^{3}, 19.4 \mu \mathrm{g} / \mathrm{m}^{3}$, and $16.7 \mathrm{ppb}$, respectively (Table 2). During the study period, the daily mean temperature was $9.8^{\circ} \mathrm{C}$, while the relative humidity was $58.0 \%$.

The concentration of $\mathrm{PM}_{10}, \mathrm{PM}_{2.5}$, and $\mathrm{NO}_{2}$ was estimated using the Community Multiscale Air Quality model. SD, standard deviation; IQR, interquartile range; $\mathrm{PM}_{10}$, particulate matter $<10 \mu \mathrm{m} ; \mathrm{PM}_{2.5}$, particulate matter $<2.5 \mu \mathrm{m} ; \mathrm{NO}_{2}$, nitrogen dioxide; ppb, parts per billion.

Predicted values of the CMAQ model using data assimilation was compared with the observations at the Korean Air Quality monitoring station (AQMS) as was shown in
Table 2 Exposure to air pollutants and meteorological indexes during the study period

Mean SD Min $\frac{\text { Percentile }}{25 \text { th 50th 75th }}$ Max IQR

\begin{tabular}{lllllllll}
\hline Daily exposures & & & & & & & & \\
$\mathrm{PM}_{10}\left(\mu \mathrm{g} / \mathrm{m}^{3}\right)$ & 42.1 & 22.0 & 3.6 & 27.2 & 37.0 & 50.7 & 152.9 & 23.5 \\
$\mathrm{PM}_{2.5}\left(\mu \mathrm{g} / \mathrm{m}^{3}\right)$ & 32.1 & 17.7 & 2.8 & 19.8 & 28.4 & 39.2 & 147.8 & 19.4 \\
$\mathrm{NO}_{2}(\mathrm{ppb})$ & 23.5 & 13.7 & 0.8 & 13.8 & 20.4 & 30.5 & 76.2 & 16.7 \\
Temperature $\left({ }^{\circ} \mathrm{C}\right)$ & 9.8 & 10.5 & -19.5 & 1.3 & 9.8 & 19.7 & 28.8 & 18.3 \\
Humidity $(\%)$ & 58.0 & 18.5 & 12.3 & 44.4 & 57.7 & 73.1 & 95.1 & 28.7 \\
\hline
\end{tabular}


Fig. S1 (Additional file 2). $\mathrm{PM}_{10}$ and $\mathrm{NO}_{2}$ were measured at all AQMSs, but the $\mathrm{PM}_{2.5}$ was only monitored in Seoul metropolitan city during 2012 and 2013. The results of the cross-validation for daily mean $\mathrm{PM}_{10}, \mathrm{PM}_{2.5}$ and $\mathrm{NO}_{2}$ are summarized in Fig. S2 (Additional file 2). They showed that CMAQ model could reproduce observations for entire region in South Korea with $\mathrm{R}^{2}$-square was 0.78 for $\mathrm{PM}_{10}, 0.59$ for $\mathrm{PM}_{2.5}$ and 0.86 for $\mathrm{NO}_{2}$ respectively.

We examined the FBG and HbA1c levels of the study participants to determine the lag effect. Figure 1 shows the changes in FBG levels per 1unit increment of $\mathrm{PM}_{10}$ and $\mathrm{PM}_{2.5}$ with a lag of up to 6 days and $\mathrm{NO}_{2}$ with a lag of up to 7 days. GAM analysis demonstrated the dose-response relationship between air quality and glucose metabolites. An increase in the FBG level was evident at $\mathrm{PM}_{10}$ of above $75 \mu \mathrm{g} / \mathrm{m}^{3}$ and $\mathrm{PM}_{2.5}$ of above $30 \mu \mathrm{g} / \mathrm{m}^{3}$. The relationship was more linear for $\mathrm{NO}_{2}$. Considering that the level of $\mathrm{HbA1c}$ represents blood glucose levels 6 to 8 weeks before the test, we observed changes in the moving average concentrations of all pollutants at 0-60 days. As the concentration of air pollutants increased, the level of
HbA1c also increased, with $\mathrm{PM}_{10}$ and $\mathrm{PM}_{2.5}$ showing a clear dose-response effect.

We divided all participants into non-diabetic and diabetic and under 65 years and 65 years or over groups to identify effect modifications. As shown in Table 3, the level of FBG was significantly increased by $0.85 \mathrm{mg} / \mathrm{dL}$ (95\% CI: $0.23-1.47$ ) per IQR increment of $\mathrm{NO}_{2}$ and the level of HbAlc was increased by $0.07 \%$ (95\% CI: $0.02-0.11)$ per IQR increment of $\mathrm{PM}_{2.5}$ in all participants. The FBG level increased by $0.36 \mathrm{mg} / \mathrm{dL}$ (95\% CI: $0.11-0.62)$ per IQR increment of $\mathrm{NO}_{2}$ in non-diabetic participants, with the peak increased being $3.32 \mathrm{mg} / \mathrm{dL}$ (95\% CI: 0.64-6.00) in diabetic individuals; however, the HbA1c levels showed no such significant changes. Conversely, exposure to $\mathrm{PM}_{10}$ and $\mathrm{PM}_{2.5}$ increased the HbA1c levels in the non-diabetic group by $0.04 \%$ (95\% CI: $0.02-0.06)$ and 0.06\% (95\% CI: 0.03-0.08), respectively. Overall, the daily change in FBG and HbA1c levels were higher in the diabetic participants.

In participants aged $\geq 65$ years, exposure to $\mathrm{NO}_{2}$ strongly increased the level of FBG $(0.39 \mathrm{mg} / \mathrm{dL} ; 95 \%$

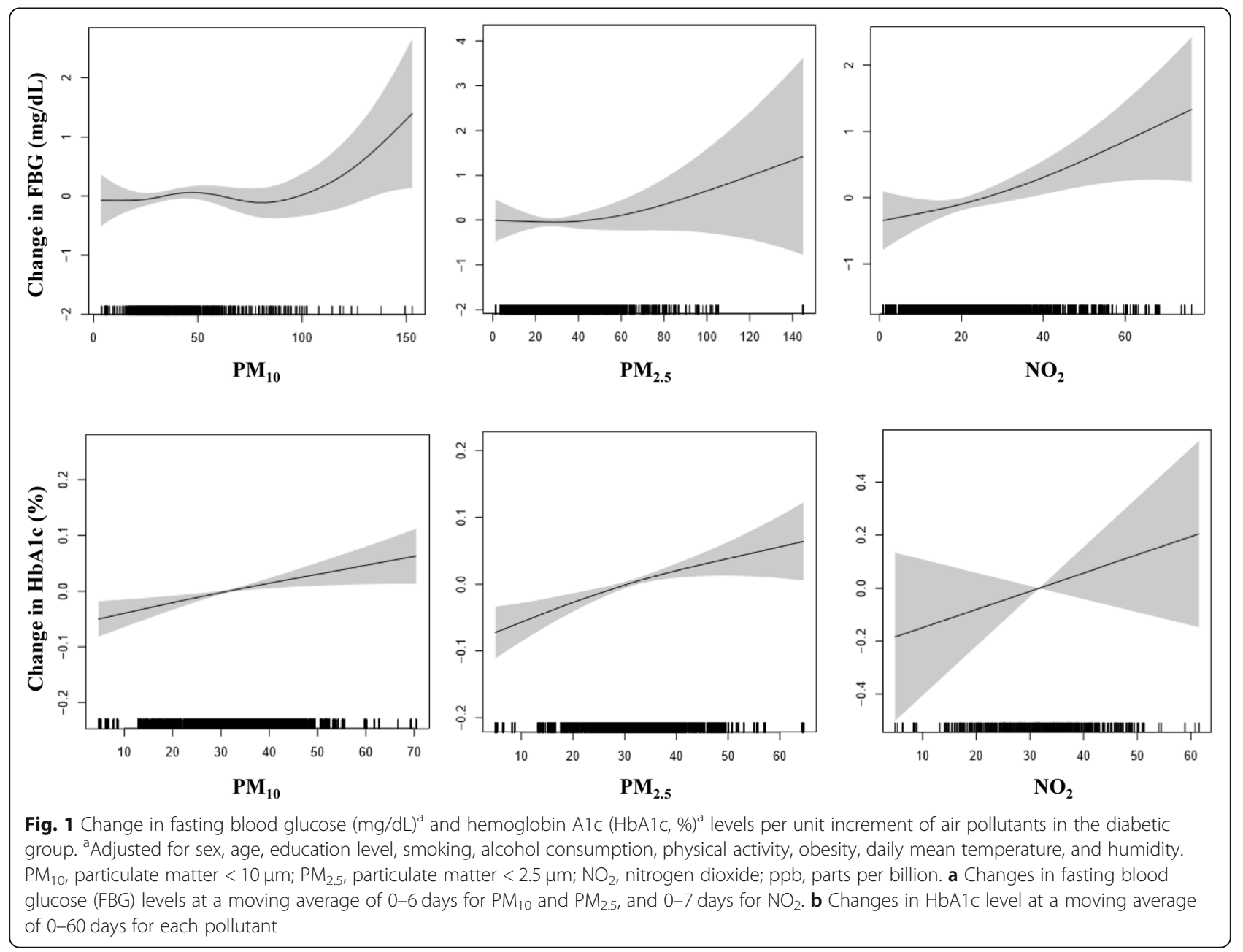


Table 3 Estimated changes in fasting blood glucose (mg/dL) and hemoglobin A1c (percentage) levels per interquartile range increment of $\mathrm{PM}_{10}, \mathrm{PM}_{2.5}$, and $\mathrm{NO}_{2}$ in all participants according to the presence of diabetes

\begin{tabular}{|c|c|c|c|c|}
\hline \multirow[t]{2}{*}{ Pollutant } & \multicolumn{2}{|c|}{ Fasting blood glucose $(\mathrm{mg} / \mathrm{dL})^{\mathbf{a}}$} & \multicolumn{2}{|c|}{ HbA1c (percentage points) ${ }^{\mathbf{a}}$} \\
\hline & $\boldsymbol{\beta}(95 \% \mathrm{Cl})$ & $p$-value & $\boldsymbol{\beta}(95 \% \mathrm{Cl})$ & $p$-value \\
\hline \multicolumn{5}{|l|}{ Total } \\
\hline $\mathrm{PM}_{10}\left(\mu \mathrm{g} / \mathrm{m}^{3}\right)$ & $0.22(-0.31-0.75)$ & 0.419 & $0.05(0.00-0.10)$ & 0.075 \\
\hline $\mathrm{PM}_{2.5}\left(\mu \mathrm{g} / \mathrm{m}^{3}\right)$ & $0.31(-0.20-0.82)$ & 0.227 & $0.07(0.02-0.11)^{*}$ & 0.002 \\
\hline $\mathrm{NO}_{2}(\mathrm{ppb})$ & $0.85(0.23-1.47)^{*}$ & 0.006 & $0.01(-0.02-0.02)$ & 0.579 \\
\hline \multicolumn{5}{|l|}{ No diabetes } \\
\hline $\mathrm{PM}_{10}\left(\mu \mathrm{g} / \mathrm{m}^{3}\right)$ & $0.00(-0.22-0.22)$ & 0.729 & $0.04(0.02-0.06)^{*}$ & $p<0.0001$ \\
\hline $\mathrm{PM}_{2.5}\left(\mu \mathrm{g} / \mathrm{m}^{3}\right)$ & $-0.09(-0.30-0.12)$ & 0.383 & $0.06(0.03-0.08)^{*}$ & $p<0.0001$ \\
\hline $\mathrm{NO}_{2}(\mathrm{ppb})$ & $0.36(0.11-0.62)^{*}$ & 0.004 & $0.01(-0.01-0.01)$ & 0.618 \\
\hline \multicolumn{5}{|l|}{ Diabetes } \\
\hline $\mathrm{PM}_{10}\left(\mu \mathrm{g} / \mathrm{m}^{3}\right)$ & $3.28(0.60-5.97)^{*}$ & 0.016 & $0.16(-0.08-0.41)$ & 0.194 \\
\hline $\mathrm{PM}_{2.5}\left(\mu \mathrm{g} / \mathrm{m}^{3}\right)$ & $2.83(0.27-5.38)^{*}$ & 0.030 & $0.15(-0.07-0.37)$ & 0.186 \\
\hline $\mathrm{NO}_{2}(\mathrm{ppb})$ & $3.32(0.64-6.00)^{*}$ & 0.015 & $0.05(-0.11-0.21)$ & 0.529 \\
\hline
\end{tabular}

${ }^{*} p$-value $<0.05$. The level of fasting blood glucose $(\mathrm{mg} / \mathrm{dL})$ per interquartile range increment at a moving average of $0-6$ days in $\mathrm{PM}_{10}$ and $\mathrm{PM} \mathrm{M}_{2.5}$ and $0-7$ days in $\mathrm{NO}_{2}$. The level of $\mathrm{HbA1c}$ (percentage) per interquartile range increment at a moving average of 0-60 days for each pollutant. ${ }^{\mathrm{a}} \mathrm{Model} 3$, adjusted for sex, age,

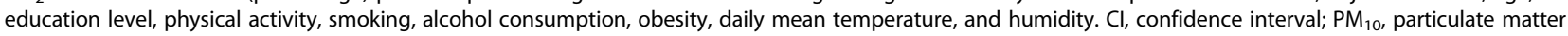
$<10 \mu \mathrm{m} ; \mathrm{PM}_{2.5}$, particulate matter $<2.5 \mu \mathrm{m} ; \mathrm{NO}_{2}$, nitrogen dioxide; ppb, parts per billion

CI: $0.12-0.66)$ not only in non-diabetic but also in diabetic individuals $(4.92 \mathrm{mg} / \mathrm{dL} ; 95 \%$ CI: $1.27-8.57)$ (Table 4). In all participants, the HbA1c level increased by $0.07 \%$ (95\% CI: $0.03-0.09$ ) with exposure to $\mathrm{PM}_{10}$ and by $0.09 \%$ (95\% CI: $0.04-0.14$ ) with exposure to $\mathrm{PM}_{2.5}$. When classified according to the presence of diabetes, significant associations were noted in the non-diabetic group $(0.07 \%$ [95\% CI: 0.01-0.12] in $\mathrm{PM}_{10}$ and $0.08 \%$ [95\% CI: 0.03-0.14] in $\mathrm{PM}_{2.5}$ ). In the diabetic group, the peak change in
HbA1c levels was $0.12 \%$ (95\% CI: 0.03-0.20) with exposure to $\mathrm{PM}_{2.5}$. Analysis of the relative moving average concentration of air pollutants considering its half-life in the human body revealed that, overall, the increase in HbA1c level was greater in the diabetic group than that in the non-diabetic group. At the same time, while mid-term exposure leads to a significant increase in the HbAlc level in the nondiabetic group. However, exposure to $\mathrm{NO}_{2}$ did not show any significant results, and the patterns of

Table 4 Estimated changes in fasting blood glucose $(\mathrm{mg} / \mathrm{dL})$ and hemoglobin A1c (percentage) level per interquartile range increment of $\mathrm{PM}_{10}, \mathrm{PM}_{2.5}$, and $\mathrm{NO}_{2}$ in participants aged $\geq 65$ years according to the presence of diabetes

\begin{tabular}{|c|c|c|c|c|}
\hline \multirow[t]{2}{*}{ Pollutant } & \multicolumn{2}{|c|}{ Fasting blood glucose $(\mathrm{mg} / \mathrm{dL})^{\mathbf{a}}$} & \multicolumn{2}{|c|}{ HbA1c (percentage points) } \\
\hline & $\overline{\boldsymbol{\beta}(95 \% \mathrm{Cl})}$ & $\boldsymbol{p}$-value & $\overline{\boldsymbol{\beta}(95 \% \mathrm{Cl})}$ & $\boldsymbol{p}$-value \\
\hline \multicolumn{5}{|l|}{ Total } \\
\hline $\mathrm{PM}_{10}\left(\mu \mathrm{g} / \mathrm{m}^{3}\right)$ & $0.76(-0.18-1.71)$ & 0.112 & $0.07(0.03-0.09)^{*}$ & $p<0.0001$ \\
\hline $\mathrm{PM}_{2.5}\left(\mu \mathrm{g} / \mathrm{m}^{3}\right)$ & $0.84(-0.10-1.77)$ & 0.078 & $0.09(0.04-0.14)^{*}$ & $p<0.0001$ \\
\hline $\mathrm{NO}_{2}(\mathrm{ppb})$ & $1.09(0.11-2.06)^{*}$ & 0.029 & $0.00(-0.02-0.01)$ & 0.445 \\
\hline \multicolumn{5}{|l|}{ No diabetes } \\
\hline $\mathrm{PM}_{10}\left(\mu \mathrm{g} / \mathrm{m}^{3}\right)$ & $0.23(-0.28-0.74)$ & 0.380 & $0.07(0.01-0.12)^{*}$ & 0.015 \\
\hline $\mathrm{PM}_{2.5}\left(\mu \mathrm{g} / \mathrm{m}^{3}\right)$ & $0.36(-0.15-0.87)$ & 0.169 & $0.08(0.03-0.14)^{*}$ & 0.001 \\
\hline $\mathrm{NO}_{2}(\mathrm{ppb})$ & $0.39(0.12-0.66)^{*}$ & 0.004 & $0.00(-0.03-0.04)$ & 0.670 \\
\hline \multicolumn{5}{|l|}{ Diabetes } \\
\hline $\mathrm{PM}_{10}\left(\mu \mathrm{g} / \mathrm{m}^{3}\right)$ & $3.64(0.69-6.59)^{*}$ & 0.015 & $0.11(0.02-0.20)^{*}$ & 0.021 \\
\hline $\mathrm{PM}_{2.5}\left(\mu \mathrm{g} / \mathrm{m}^{3}\right)$ & $3.96(0.06-7.85)^{*}$ & 0.046 & $0.12(0.03-0.20)^{*}$ & 0.016 \\
\hline $\mathrm{NO}_{2}(\mathrm{ppb})$ & $4.92(1.27-8.57)^{*}$ & 0.008 & $0.02(-0.03-0.08)$ & 0.440 \\
\hline
\end{tabular}

${ }^{*} p$-value $<0.05$. The level of fasting blood glucose $(\mathrm{mg} / \mathrm{dL})$ per interquartile range increment at a moving average of $0-6$ days for $\mathrm{PM}_{10}$ and $\mathrm{PM}_{2.5}$ and at $0-7$ days for $\mathrm{NO}_{2}$. The level of $\mathrm{HbA} 1 \mathrm{c}$ (percentage points) per interquartile range increment at a moving average of $0-60$ days for each pollutant. ${ }^{\mathrm{a}} \mathrm{Model} 3$, adjusted for sex, age, education level, physical activity, smoking, alcohol consumption, obesity, and daily mean temperature and humidity. $\mathrm{Cl}$ confidence interval; $P M_{10}$ particulate matter $<10 \mu \mathrm{mM}, P M_{2.5}$, particulate matter $<2.5 \mu \mathrm{m} ; \mathrm{NO}_{2}$ nitrogen dioxide, $p p b$ parts per billion 
change in blood glucose markers were similar for $\mathrm{PM}_{10}$ and $\mathrm{PM}_{2.5}$.

Based on the overall results, we performed a subgroup analysis based on sex and found that FBG levels were the highest in diabetic male aged 65 years and over (5.32 $\mathrm{mg} / \mathrm{dL}$ [95\% CI: $1.22-9.41$ ] for $\mathrm{PM}_{10}$ and $4.69 \mathrm{mg} / \mathrm{dL}$ [95\% CI: 0.48-8.91] for $\mathrm{PM}_{2.5}$ ) with a lag of up to six days and five days, respectively, but did not differ significantly in female (Fig. 2). In particular, according to the level of daily exposure to $\mathrm{NO}_{2}$, the highest increase was by $7.83 \mathrm{mg} / \mathrm{dL}$ (95\% CI: $2.80-12.87$ ) in males with a lag of up to 6 days. Although the HbA1c level did not increase significantly with exposure to $\mathrm{NO}_{2}$, it increased with exposure to $\mathrm{PM}_{10}$ and $\mathrm{PM}_{2.5}$. The highest increase (0.57, 95\% CI: 0.04-1.09) occurred for $\mathrm{PM}_{10}$ at a moving average of $0-60$ days and at $0-75$ days and $0-90$ days for
$\mathrm{PM}_{2.5}$ (0.34, 95\% CI: $0.04-0.63$ and 0.34, 95\% CI: $0.05-$ 0.64 , respectively).

\section{Discussion}

We explored the effects of short-term exposure to air pollution on changes in FBG levels and mid-term exposure on changes in $\mathrm{HbA} 1 \mathrm{c}$ levels considering effect modifiers using the KNHANES data combined with CMAQ modeling to determine the level of exposure to air pollution. The level of exposure was calculated according to the same administrative districts in which the survey had been conducted. The findings obtained from our study indicated that the levels of FBG and HbA1c were more sensitive to exposure to air pollution in males and that the susceptible groups were the elderly with diabetes.

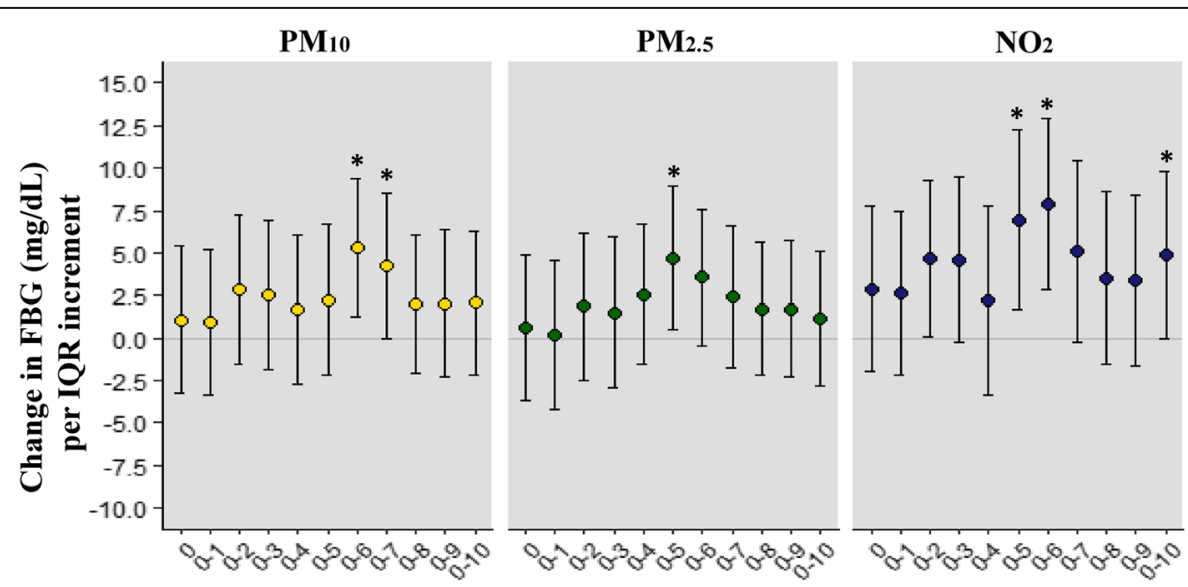

Exposure window before blood test (days)

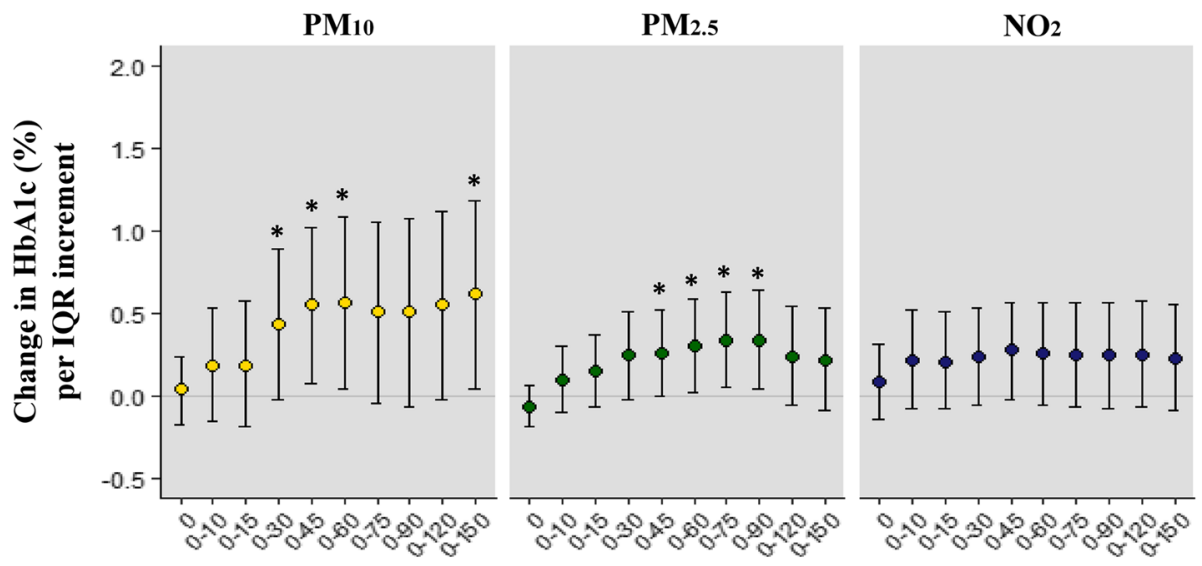

Exposure window before blood test (days)

Fig. 2 Associations between changes in fasting blood glucose $(\mathrm{mg} / \mathrm{dL})^{\mathrm{a}}$ and $\mathrm{HbA1c}(\%)^{\mathrm{a}}$ levels per interquartile range increment of $\mathrm{PM}_{10}, \mathrm{PM}_{2.5}$, and $\mathrm{NO}_{2}$ in diabetic male aged $\geq 65$ years. ${ }^{*} p<0.05$. ${ }^{a}$ Adjusted for age, education level, smoking, alcohol consumption, physical activity, obesity, daily mean temperature, and humidity. $\mathrm{PM}_{10}$, particulate matter $<10 \mu \mathrm{m} ; \mathrm{PM}_{2.5}$, particulate matter $<2.5 \mu \mathrm{m}$; $\mathrm{NO}_{2}$, nitrogen dioxide; ppb, parts per billion. 0 , date of blood test; $0-15$, moving average from days 0 to 15; $0-30$, moving average from days 0 to 30; $0-45$, moving average from days 0 to $45 ; 0-60$, moving average from days 0 to $60 ; 0-75$, moving average from days 0 to $75 ; 0-90$, moving average from days 0 to $90 ; 0-120$, moving average from days 0 to 120; $0-150$, moving average from days 0 to 150 
Previous studies showed the association of pathophysiologic pathways and glucose metabolism with air pollution. Inhaled air pollutants induce oxidative stress and inflammation in the lungs and damage other organ systems, including the adipose tissue [41-44]. This inflammation negatively affects the insulin signaling pathways that regulate glucose metabolism, resulting in disruption of blood glucose regulation and an abnormal increase in glucose level. In diabetic participants with high insulin insensitivity, a dramatic increase in FBG and HbA1c levels occurs due to the influx of harmful substances. Based on this evidence, epidemiological studies on the increased prevalence of DM due to exposure to harmful substances in ambient air and changes in biological factors related to diabetes are actively conducted. The findings of the present study were consistent with those of previous studies. Kim and Hong [5] reported that in elderly Koreans with a history of DM, based on IQR increments of $\mathrm{PM}_{10}$ and $\mathrm{NO}_{2}$, the FBG levels were elevated by $7.74 \mathrm{mg} / \mathrm{dL}$ and $9.90 \mathrm{mg} / \mathrm{dL}$, respectively. In comparison, we observed an increase of $8.74 \mathrm{mg} / \mathrm{dL}$ per $23.5 \mu \mathrm{g} /$ $\mathrm{m}^{3}$ increment in $\mathrm{PM}_{10}$ and $15.32 \mathrm{mg} / \mathrm{dL}$ per $16.7 \mathrm{ppb}$ increment of $\mathrm{NO}_{2}$ in diabetic male aged 65 years and over in the present study. Although our values were slightly lower, the results were similar to those reported in Kim and Hong's study. While the sensitivity of the vulnerable groups varied according to the level of air pollution exposure in each country and differences in living environments, we compared the sensitivity with that reported in studies from other countries. Liu et al. reported increase in FBG level of $2.20 \mathrm{mg} / \mathrm{dL}$ and HbA1c level of $0.04 \%$ with a $19.4 \mu \mathrm{g} / \mathrm{m}^{3}$ increment in $\mathrm{PM}_{2.5}$ [17]. Chuang et al. reported an estimated change in HbA1c level of $0.06 \%$ per $34 \mu \mathrm{g} / \mathrm{m}^{3}$ increment following short-term exposure to $\mathrm{PM}_{10}$ [20]. When the IQR values of our study were applied, the change of HbA1c in Chuang et al.'s study was $0.04 \%$, which was slightly lower than that in our study. In the study by Lucht et al., the same exposure period as in our study was applied but not in the diabetic group [23]. For 91-day exposure, a $4 \mu \mathrm{g} / \mathrm{m}^{3}$ increment in $\mathrm{PM}_{2.5}$ elevated the HbA1c level by $0.07 \%$, while a $5.5 \mu \mathrm{g} / \mathrm{m}^{3}$ increment in $\mathrm{PM}_{10}$ increased the $\mathrm{HbA1c}$ level by $0.04 \%$; no significant changes were observed with exposure to $\mathrm{NO}_{2}$, as in our results. In a study in northern France, which accessed long-term exposure to air pollution and HbA1c levels, based on which we converted the exposure level in South Korea, the level of HbA1c increased by $0.52 \%$ per $23.5 \mu \mathrm{g} / \mathrm{m}^{3}$ increment of $\mathrm{PM}_{10}$, similar to that shown in the current study [45].

The FBG level was altered with short-term exposure, especially in diabetic males aged 65 years or more. This population was sensitive to exposure to $\mathrm{PM}_{10}$ and $\mathrm{PM}_{2.5}$ but more responsive to $\mathrm{NO}_{2}$ exposure, with an increase of $7.83 \mathrm{mg} / \mathrm{dL}$ (95\% CI: $2.80-12.87$ ) per IQR increment of $\mathrm{NO}_{2}$. Considering that $\mathrm{HbA1c}$ represents the average blood glucose level over a few months, it revealed significant changes according to exposure at a moving average of $0-45,60$, and 75 days in diabetic males aged 65 years or more, which is consistent with the results of previous studies. Considering that an increase in $\mathrm{HbA1c}$ level of $1 \%$ corresponds to an average FBG level increase of $35 \mathrm{mg} / \mathrm{dL}$, a change in HbA1c level cannot be considered small. This observation also suggests that both short-term and mid-term exposure can significantly increase the risk of diabetes. Although most significant results were shown in males aged over 65 years in the present study, the risk of DM in females cannot be neglected. The sexual difference in the health effects of air pollutants may be attributable to hormonal characteristics in addition to the differences in the frequency of exposure to pollutants over their lifetime. In a previous study, middle-aged males with higher serum testosterone levels and sex hormone-binding globulin had high insulin sensitivity, which was independent of baseline insulin levels, body weight, and fat [46]. Lower than normal serum testosterone levels caused by hypogonadism increased the risk of developing glucose metabolic disorders and metabolic syndrome [47]. Previous studies reported that the serum testosterone levels in nearly $80 \%$ of men, age 60 to 80 years, decrease rapidly every ten years until such time that they become testosterone deficient $[48,49]$. The effects of these factors could be more pronounced owing to synergistic and cumulative effects in an elderly male with relatively high exposure to hazardous substances due to ambient air pollution. Results of the present study confirm this association based on the observed increased effect of air pollution exposure on diabetes-related blood markers in vulnerable groups in contrast to that in non-diabetic individuals. The inhalation of toxic substances in individuals with compromised metabolic function due to chronic diseases may disrupt glucose homeostasis by weakening the immune system and further decreasing metabolic function.

We observed changes in diabetes-related parameters caused by exposure to air pollution in consideration of effect modifiers; such effects were also noted in the absence of diabetes. Peng et al. and Lucht et al. observed significantly elevated FBG levels in non-diabetic participants; they concluded that the effects of air pollution might be relatively minor in diabetic individuals who consume a well-balanced diet, who perform physical activities, and who receive insulin or hypoglycemic agents $[18,23]$. These findings suggest that more attention should be paid in managing the susceptible groups in a community rather than for early screening of the entire population. The trend of changes in FBG and HbA1c levels caused by air pollution were not similar. In 
particular, unlike FBG, the HbA1c level did not show any significant effect of exposure to $\mathrm{NO}_{2}$ and was more affected by fine particulate matter, as shown in some previous studies $[23,50]$.

Most studies on the health effects of air pollution in South Korea were conducted using atmospheric environmental data measured at domestic monitoring sites, which are mostly installed in metropolitan or industrial areas. In terms of health administration units, only half of the units have air monitoring posts. There is a limitation in identifying health effects based on health index generated at the local level every year. Generally, airborne exposure data collected from domestic monitoring sites are lower in value than the actual exposure levels in areas without monitoring sites [51]. To overcome these problems, we used the KAQFS and CMAQ data to match the survey areas of the KNHANES. Finally, the currently available KAQFS and CMAQ data only show the results within two years; hence, long-term data were not available for this study. The level of air pollution varies each year, and there is a need to understand the longer-term variations to obtain more accurate results. In addition, previous studies reported that the trafficrelated air pollution increase the risk of $\mathrm{DM}[9,11,16]$. It is necessary to build a model of air pollutants emitted from major roads such as the Land Use Regression model to present an increased risk of diabetic-related indicators following exposure to the ambient air pollution.

The greatest strength of our analysis is owing to the nationwide survey which is well standardized with good quality control.. In Korea, studies on diabetesrelated metabolism and exposure to ambient air pollution have not been conducted except for that conducted by Kim and Hong [5]. Our study was based on a national survey of the population, allowing a comparison with other countries. In particular, our analysis was based on the results of blood tests obtained from examinations performed during the KNHANES, a typical nationwide survey with reasonable quality control, which is performed annually through a systematic quality control system [25].

Second, we generated air pollution exposure data for health administrative districts that were surveyed using modeling data and matched these data to the residential address of the participants and the exact date of the blood test. The date of the blood test was used to identify changes in the FBG level due to short-term exposure to air pollution and that in HbA1c level due to mid-term exposure. Our findings provide a potential explanation for why diabetic individuals are at a higher risk for DM due to acute exposure to air pollution, although the effects on glucose metabolism of short- and mid-term exposure to air pollution may differ from chronic effects.
Third, we estimated the effects of air pollution on diabetes-related indicators in terms of effect modifiers using KNHANES data extracted based on sample design guidelines. Although the disruption in glucose metabolism owing to ambient air pollution has been reported worldwide, these effects are observed in susceptible subpopulations more rather than in the entire population. Based on previous studies, we stratified all participants according to effect modifiers to define sensitive group and compared the effects on each vulnerable group to estimate the representative values. The findings of the current study suggest that the groups susceptible to DM due to air pollution should be clearly defined and that approaches for the prevention of chronic diseases should be developed.

We found that there is a strong association between the short-term exposure to air pollution and diabetesrelated factors in adults over the age of 20. This suggests that this continuous exposure affects the metabolism of insulin, including FBG and $\mathrm{HbA1c}$, and may be a risk factor for the development of metabolic diseases such as glucose intolerance or type 2 diabetes later in life. In addition, risk factors for diabetes metabolism, including insulin resistance, are rarely perceived as harmful in early life, but over time, such as long-term exposure, it can be tracked the risk of DM and lead to higher risks $[52,53]$. Therefore, based on our findings, it suggests that scientific evidence should be established based on studies on the risks of metabolic-related factors from short-term and long-term exposure to air pollution in South Korea.

The rapid industrialization of South Korea and surrounding East Asian areas has led to increased air pollution, which is a major environmental problem. Specifically, there is concern regarding the adverse health effects of long-term exposure to air pollution. In the present study, we quantitatively assessed the health effects at the local level by combining atmospheric data and health behavior indices and biomarkers in the KNHANES performed in health administrative districts annually. Considering the increasing incidence of diabetes as a chronic disease and an increase in air pollution in South Korea, policy changes to reduce the health effects caused by exposure to air pollution in the elderly population are necessary for adequate health and environment management. Evaluation of the risk of diabetes and chronic diseases due to exposure to air pollution in susceptible populations in advance can be used to develop customized preventive programs at the local level.

\section{Conclusion}

We found an increased risk of elevated blood glucose levels with short- and mid-term exposure to air pollution, which was more prominent among diabetic males 
aged $\geq 65$ years in South Korea. These results suggest that policy changes should be made for adequate health and environment management in order to reduce the health effects of air pollution on elderly people and the increasing prevalence of diabetes, taking into account the severity of chronic diseases and air pollution.

\section{Supplementary information}

Supplementary information accompanies this paper at https://doi.org/10. 1186/s12940-020-00623-9.

Additional file 1: Table S1. Estimated the Akaike Information Criterion (AIC) for model selection with covariates. Table S2. Associations between ambient air pollution and the level of fasting blood glucose level (mg/dL) and hemoglobin A1c (percentage points) per interquartile range of $\mathrm{PM}_{10}, \mathrm{PM}_{2.5}$, and $\mathrm{NO}_{2}$. (DOCX $17 \mathrm{~kb}$ )

Additional file 2: Figure S1. The location of the Korean Air Quality monitoring stations (AQMS) in South Korea with highlighted box of Seoul Metropolis. Figure S2. The results of cross-validation for daily mean concentration of PM10, PM2.5, and NO2 in South Korea during 2012 and 2013. x-axis: observed values. $y$-axis: predicted values.

\section{Abbreviations}

AQMS: Air Quality monitoring station; BMI: Body mass index; Cl: Confidence interval; CMAQ: Community Multiscale Air Quality; DM: Diabetes mellitus; FBG: Fasting blood glucose; GAM: Generalized additive model; HbA1c: Hemoglobin A1c; IQR: Interquartile range; KNHANES: Korea National Health and Nutrition Examination Survey; KAQFS: Korean Air Quality Forecasting System; $\mathrm{NO}_{2}$ : Nitrogen dioxide; PPB: Parts per billion; $\mathrm{PM}_{10}$ : Particulate matter $<10 \mu \mathrm{m} ; \mathrm{PM}_{2.5}$ : Particulate matter $<2.5 \mu \mathrm{m}$; SES: Socioeconomic status

\section{Acknowledgements}

The data in the current study are based on the research project "Health impacts of air pollution in Korea," which was conducted from 2014 to 2016 granted by the Korea Centers for Disease Control and Prevention (no. 2014ER270502).

\section{Authors' contributions}

Conceived and designed the experiments: MJH, HKC, YSK, and HYY Performed the experiments: MJH, JHK, YSK, and HYY. Analyzed the data: MJH, YSK, and HYY. Contributed reagents/materials/analysis tools: MJH, YSK, and HYY. Wrote the paper: MJH, HKC, and YSK. The author(s) read and approved the final manuscript.

\section{Funding}

This research was supported by the Korea Centers for Disease Control and Prevention (no. 2014ER270502).

\section{Availability of data and materials}

Not applicable.

\section{Ethics approval and consent to participate}

The present study was approved by the institutional reviews board (IRB) of Sungkyunkwan University (IRB no. 2018-10-020).

\section{Consent for publication}

Not applicable.

\section{Competing interests}

The authors declare that they have no competing interests.

\section{Author details}

'Department of Social and Preventive Medicine, Sungkyunkwan University School of Medicine, 2066 Seobu-ro Jangan-gu, Suwon, Gyeonggi-do 16419, Republic of Korea. ${ }^{2}$ Department of Environmental and Energy Engineering, Anyang University, Anyang, South Korea.
Received: 19 February 2020 Accepted: 8 June 2020

Published online: 17 June 2020

\section{References}

1. Lim SS, Vos T, Flaxman AD, Danaei G, Shibuya K, Adair-Rohani H, et al. A comparative risk assessment of burden of disease and injury attributable to 67 risk factors and risk factor clusters in 21 regions, 1990-2010: a systematic analysis for the global burden of disease study 2010. Lancet. 2012:380:2224-60.

2. World Health Organization. Air quality guidelines: global update 2005 (particulate matter, ozone, nitrogen dioxide, and sulfur dioxide). WHO Regional Office for Europe, Copenhagen 2006.

3. Raaschou-Nielsen O, Sørensen M, Ketzel M, Hertel O, Loft S, Tjønneland A et al. Long-term exposure to traffic-related air pollution and diabetesassociated mortality: a cohort study. Diabetologia. 2013;56:36-46.

4. Goldberg MS, Burnett RT, Yale JF, Valois MF, Brook JR. Associations between ambient air pollution and daily mortality among persons with diabetes and cardiovascular disease. Environ Res. 2006:100:255-67.

5. Kim JH, Hong YC. GSTM1, GSTT1, and GSTP1 polymorphisms and associations between air pollutants and markers of insulin resistance in elderly Koreans. Environ Health Perspect. 2012;120:1378-84

6. Eze IC, Imboden M, Kumar A, Adam M, von Eckardstein A, Stolz D, et al. A common functional variant on the pro-inflammatory Interleukin- 6 gene may modify the association between long-term $\mathrm{PM}_{10}$ exposure and diabetes. Environ Health. 2016;15:39.

7. Sun Q, Zhang G, Chen R, Li R, Wang H, Jiang A, et al. Central IKK2 inhibition ameliorates air pollution-mediated hepatic glucose and lipid metabolism dysfunction in mice with type II diabetes. Toxicol Sci. 2018;164:240-9.

8. Seaton A, Soutar A, Crawford V, Elton R, McNerlan S, Cherrie J, et al. Particulate air pollution and the blood. Thorax. 1999:54:1027-32.

9. Brook RD, Jerrett M, Brook JR, Bard RL, Finkelstein MM. The relationship between diabetes mellitus and traffic-related air pollution. J Occup Environ Med. 2008:50:32-8.

10. Pearson JF, Bachireddy C, Shyamprasad S, Goldfine AB, Brownstein JS. Association between fine particulate matter and diabetes prevalence in the U.S. Diabetes care. 2010;33:2196-201.

11. Krämer U, Herder C, Sugiri D, Strassburger K, Schikowski T, Ranft U, et al. Traffic-related air pollution and incident type 2 diabetes: results from the SALIA cohort study. Environ Health Perspect. 2010;118:1273-9.

12. Andersen ZJ, Raaschou-Nielsen O, Ketzel M, Jensen SS, Hvidberg M, Loft S. Diabetes incidence and long-term exposure to air pollution: a cohort study. Diabetes Care. 2012;35:92-8.

13. Puett RC, Hart JE, Schwartz J, Hu FB, Liese AD, Laden F. Are particulate matter exposures associated with risk of type 2 diabetes? Environ Health Perspect. 2010;119:384-9.

14. Chen H, Burnett RT, Kwong JC, Villeneuve PJ, Goldberg MS, Brook RD, et al. Risk of incident diabetes in relation to long-term exposure to fine particulate matter in Ontario. Canada Environ Health Perspect. 2013;121 804-10

15. Eze IC, Schaffner E, Fischer E, Schikowski T, Adam M, Imboden M, et al. Long-term air pollution exposure and diabetes in a population-based Swiss cohort. Environ Int. 2014;70:95-105.

16. Teichert T, Vossoughi M, Vierkötter A, Sugiri D, Schikowski T, Schulte T, et al. Association between traffic-related air pollution, subclinical inflammation and impaired glucose metabolism: results from the SALIA study. PLoS One. 2013:8:e83042

17. Liu C, Yang C, Zhao Y, Ma Z, Bi J, Liu Y, et al. Associations between longterm exposure to ambient particulate air pollution and type 2 diabetes prevalence, blood glucose and glycosylated hemoglobin levels in China. Environ Int. 2016;92-93:416-21.

18. Peng C, Bind MAC, Colicino E, Kloog I, Byun HM, Cantone L, et al. Particulate air pollution and fasting blood glucose in nondiabetic individuals: associations and epigenetic mediation in the normative aging study, 20002011. Environ Health Perspect. 2016;124:1715-21

19. Chen L, Zhou Y, Li S, Williams G, Kan H, Marks GB, et al. Air pollution and fasting blood glucose: a longitudinal study in China. Sci Total Environ. 2016; 541:750-5.

20. Chuang KJ, Yan YH, Cheng TJ. Effect of air pollution on blood pressure, blood lipids, and blood sugar: a population-based approach. J Occup Environ Med. 2010;52:258-62. 
21. O'Neill MS, Veves A, Sarnat JA, Zanobetti A, Gold DR, Economides PA, et al. Air pollution and inflammation in type 2 diabetes: a mechanism for susceptibility. Occup Environ Med. 2007;64:373-9.

22. Dubowsky SD, Suh H, Schwartz J, Coull BA, Gold DR. Diabetes, obesity, and hypertension may enhance associations between air pollution and markers of systemic inflammation. Environ Health Perspect. 2006;114:992-8.

23. Lucht SA, Hennig F, Matthiessen C, Ohlwein S, Icks A, Moebus S, et al. Air pollution and glucose metabolism: an analysis in non-diabetic participants of the Heinz Nixdorf recall study. Environ Health Perspect. 2018;126:047001.

24. Toledo-Corral CM, Alderete TL, Habre R, Berhane K, Lurmann FW, Weigensberg MJ, et al. Effects of air pollution exposure on glucose metabolism in Los Angeles minority children. Pediatr Obes. 2018;13:54-62.

25. Kim Y. The Korea National Health and nutrition examination survey (KNHANES): current status and challenges. Epidemiol Health. 2014;36: e2014002.

26. Kweon S, Kim Y, Jang MJ, Kim Y, Kim K, Choi S, et al. Data resource profile: the Korea national health and nutrition examination survey (KNHANES). Int J Epidemiol. 2014;43:69-77.

27. Patra J, Jha P, Rehm J, Suraweera W. Tobacco smoking, alcohol drinking, diabetes, low body mass index and the risk of self-reported symptoms of active tuberculosis: individual participant data (IPD) meta-analyses of 72,684 individuals in 14 high tuberculosis burden countries. PLoS One. 2014;9: e96433.

28. Yeh HC, Duncan BB, Schmidt MI, Wang NY, Brancati FL. Smoking, smoking cessation, and the risk for type 2 diabetes mellitus: a cohort study. Ann Intern Med. 2010;152:10-7.

29. Rimm EB, Chan J, Stampfer MJ, Colditz GA, Willett WC. Prospective study of cigarette smoking, alcohol use, and the risk of diabetes in men. BMJ. 1995: 310:555-9.

30. Mokdad AH, Ford ES, Bowman BA, Dietz WH, Vinicor F, Bales VS, et al. Prevalence of obesity, diabetes, and obesity-related health risk factors, 2001. JAMA. 2003;289:76-9.

31. Dandona P, Aljada A, Chaudhuri A, Mohanty P, Garg R. Metabolic syndrome: a comprehensive perspective based on interactions between obesity, diabetes, and inflammation. Circulation. 2005;111:1448-54.

32. Koo YS, Kim ST, Yun HY, Han JS, Lee JY, Kim KH, et al. The simulation of aerosol transport over East Asia region. Atmospheric Res. 2008;90:264-71.

33. Koo YS, Kim ST, Cho JS, Jang YK. Performance evaluation of the updated air quality forecasting system for Seoul predicting $\mathrm{PM}_{10}$. Atmospheric Res. 2012; 58:56-69.

34. Koo YS, Choi DR, Kwon HY, Jang YK, Han JS. Improvement of $\mathrm{PM}_{10}$ prediction in East Asia using inverse modeling. Atmospheric Environ. 2015; 106:318-28.

35. Koo YS, Yun HY, Choi DR, Han JS, Lee JB, Lim YJ. An analysis of chemical and meteorological characteristics of haze events in the Seoul metropolitan area during January 12-18, 2013. Atmospheric Environ. 2018;178:87-100.

36. Choi DR, Yun HY, Koo YS. A development of air quality forecasting system with data assimilation using surface measurements in East Asia. J Korean Soc Atmos Environ. 2019;35:60-85.

37. Hwang MJ, Cheong HK, Kim JH, Koo YS, Yun HY. Ambient air quality and subjective stress level using community health survey data in Korea. Epidemiol Health. 2018;40:e2018028.

38. Franco RS. Measurement of red cell lifespan and aging. Transfus Med Hemother. 2012:39:302-7.

39. Jovanovic L, Peterson CM. The clinical utility of glycosylated hemoglobin. Am J Med. 1981;70:331-8.

40. Boden G, Master RW, Gordon SS, Shuman CR, Owen OE. Monitoring metabolic control in diabetic outpatients with glycosylated hemoglobin. Ann Intern Med. 1980;92:357-60.

41. Rajagopalan S, Brook RD. Air pollution and type 2 diabetes: mechanistic insights. Diabetes. 2012;61:3037-45

42. Rao X, Patel P, Puett R, Rajagopalan S. Air pollution as a risk factor for type 2 diabetes. Toxicol Sci. 2015;143:231-41.

43. Sun Q, Wang A, Jin X, Natanzon A, Duquaine D, Brook RD, et al. Acceleration of atherosclerosis and vascular inflammation in an animal model. JAMA. 2005;294:3003-10.

44. Haberzettl P, OToole TE, Bhatnagar A, Conklin DJ. Exposure to fine particulate air pollution causes vascular insulin resistance by inducing pulmonary oxidative stress. Environ Health Perspect. 2016;124:1830-9.

45. Riant M, Meirhaeghe A, Giovannelli J, Occelli F, Havet A, Cuny D, et al. Associations between long-term exposure to air pollution, glycosylated hemoglobin, fasting blood glucose and diabetes mellitus in northern France. Environ Int. 2018:120:121-9.

46. Muller M, Grobbee DE, den Tonkelaar I, Lamberts SW, van der Schouw YT. Endogenous sex hormones and metabolic syndrome in aging men. J Clin Endocrinol Metab. 2005;90:2618-23.

47. Vermeulen A, Verdonck L, Kaufman JM. A critical evaluation of simple methods for the estimation of free testosterone in serum. J Clin Endocrinol Metab. 1999;84:3666-72.

48. Laaksonen DE, Niskanen L, Punnonen K, Nyyssönen K, Tuomainen TP, Valkonen VP, et al. Testosterone and sex hormone-binding globulin predict the metabolic syndrome and diabetes in middle-aged men. Diabetes Care. 2004;27:1036-41.

49. Harman SM, Metter EJ, Tobin JD, Pearson J, Blackman MR. Longitudinal effects of aging on serum total and free testosterone levels in healthy men. J Clin Endocrinol Metab. 2001:86:724-31.

50. Tamayo T, Rathmann W, Stahl-Pehe A, Landwehr S, Sugiri D, Krämer U, et al. No adverse effect of outdoor air pollution on $\mathrm{HbA1c}$ in children and young adults with type 1 diabetes. Int J Hyg Environ Health. 2016;219:349-55.

51. Kim YM, Kim J, Han Y, Lee BJ, Choi DC, Cheong HK, et al. Comparison of diverse estimation methods for personal exposure to air pollutants and associations with allergic symptoms: the Allergy \& Gene-Environment Link (ANGEL) study. Sci Total Environ. 2016;579:1127-36.

52. Madhloum N, Janssen BG, Martens DS, Saenen ND, Bijnens E, Gyselaers W et al. Cord plasma insulin and in utero exposure to ambient air pollution. Environ Int. 2017;105:126-32.

53. Thiering E, Cyrys J, Kratzsch J, Meisinger C, Hoffmann B, Berdel D, et al. Long-term exposure to traffic-related air pollution and insulin resistance in children: results from the GINIplus and LISAplus birth cohorts. Diabetologia. 2013:56:1696-704

\section{Publisher's Note}

Springer Nature remains neutral with regard to jurisdictional claims in published maps and institutional affiliations.
Ready to submit your research? Choose BMC and benefit from:

- fast, convenient online submission

- thorough peer review by experienced researchers in your field

- rapid publication on acceptance

- support for research data, including large and complex data types

- gold Open Access which fosters wider collaboration and increased citations

- maximum visibility for your research: over $100 \mathrm{M}$ website views per year

At $\mathrm{BMC}$, research is always in progress.

Learn more biomedcentral.com/submissions 